\title{
Strategic quality planning and its impact on patients satisfaction: Empirical evidence from private health care sector of Pakistan
}

\author{
Mudassar bilal ${ }^{1}$, Dr Hummayoun Naeem ${ }^{2}$ \\ ${ }^{I}$ (Master of Business Administration in Human resource Management, Foundation University Rawalpindi \\ Campus (FURC) new lalazar Rawalpindi cantt, Pakistan) \\ ${ }_{2}^{2}$ (Head of Department of Management sciences, Foundation University Rawalpindi Campus ( FURC) new \\ lalazar Rawalpindi cantt, Pakistan)
}

Abstract: Strategic quality planning is considered as essential in today's global competition. Limited work has been conducted on SQPP (Strategic quality planning process).This paper describes the strategic quality planning and its impact on private health care sector of Pakistan.

Keywords: strategic quality planning, patient's satisfaction, Pakistani private health care sector

\section{Introduction}

Strategic quality planning is one of the most important features of the modern management styles."Strategic planning is an organization's process of defining its strategy or direction and making decisions on allocating its resources to pursue this strategy".

In order to make future decisions or determining the future direction of the organization it is very important to know its current status or position with the help of which it can follow its particular course of action .Generally strategic planning deals with one of the following three key questions:

1. What do we do?

2. For whom do we do it?

3. How do we excel?

Strategic planning process helps many organizations to determine that where they would be going in the next year (short term) or in future 3to5 years (long term) although some extend their vision to 20 years. So by future forecasting they are able to implement successful plans which in result generate profitable results.

"Strategic quality planning (SQP) is a systematic approach to defining long-term business goals, including goals to improve quality and the means (i.e., the plans) to achieve them". (Joseph A. De Feo).

How an organization can do strategic quality planning?

The process starts with the principles that quality and customer satisfaction are the center of an organization's future. It brings together all the key stakeholders.

The strategic planning can be performed by any organization. It can be highly effective, allowing the organizations to do the right thing at the right time, every time.

There are seven steps to strategic Quality Planning:

1. Discover customer needs.

2. Customer positioning.

3. Predict the future.

4. Gap analysis.

5. Closing the gap.

6. Alignment.

7. Implementation.

SQP (Strategic Quality Planning)Process will move the organization or a department's quality management team beyond the notion of quick fixes and into the realm of solutions. It leads to the development of Quality Management Strategies.

This process starts with defining what "quality" may mean to organization or department and continues with a process for developing quality standards, creating a vision for quality and translating the vision into a series of quality strategies and will take quality team through a process to:

1. Review the organization's or department's strategic plan or imperatives

2. Identify what quality initiatives or strategies have been used in the past

3. Understand the voice of customer

4. Engage employees and gain their feedback to ensure their continued commitment to quality

5. Create the quality vision

6. Develop a statement of quality and standards 
7. Identify the quality strategies

8. Develop the strategic implementation plan.

By applying all the above mentioned seven steps of strategic quality planning an organization can achieve its long term objectives as well as its set goals in a sense organization can achieve maximum profit. Strategic quality planning leads to patient's satisfaction in the health care centers as the quality standards are high in term of services etc then there will be high patient's satisfaction.

\section{Problem Statement}

Keeping the above discussion in a view, the researcher plans to study the impact of strategic quality planning on patient's satisfaction in the private health care sector of Pakistan.

\section{Originality Of The Study}

The research area that is the strategic quality planning and its impact on patient's satisfaction in the private health care sector of Pakistan has not yet been explored by any researcher so far. This is a visible gap in the body of knowledge. The present research does fill this gap and is significant contribution to the body of knowledge.

\section{Applied Aspects}

Patient satisfaction is the prime target of every health care organization/sector whatever strategies and policies that are developed are meant for the satisfaction of the patients. The study has various applied aspects. Findings of the research may me communicate to the private health care authorities for implementation in the private health care sector of Pakistan to increase the number of satisfied as well as loyal patients.

\section{Objectives Of The Study}

The objectives of the study are as follows:

1. To study the impact of strategic quality planning in the private health care sector of Pakistan.

2. To study the level of patients satisfaction in the same population

3. To examine if there is any relationship between the two variables, that is strategic quality planning (independent) and patient's satisfaction (dependent).

\section{Literature Review}

Patient satisfaction is multifaceted and a very challenging thing to define. The expectations of patient about care and attitudes contribute greatly to satisfaction; factors including pain and depression are some of the other psychosocial factors which are also known to contribute to patient satisfaction scores.

Patient satisfaction is the patient's perception regarding a particular service according to his/her already set expectations. When the patients would feels that they are being offered services according to their expectations? That don the efficiency depends a lot on the efficiency levels of the service providers. How would the efficiency level go up? This is possible through autonomy, responsibility, innovation and information (yang and choi, 2009). Patient satisfaction is a key determinant of quality of care and an important component of payfor-performance metrics.

From the above all discussion it is concluded that strategic quality planning can contribute a lot towards the business growth and development. Health care sectors are largely dependent upon the patient's satisfaction and patient's satisfaction is one of the end products of the strategic quality planning.

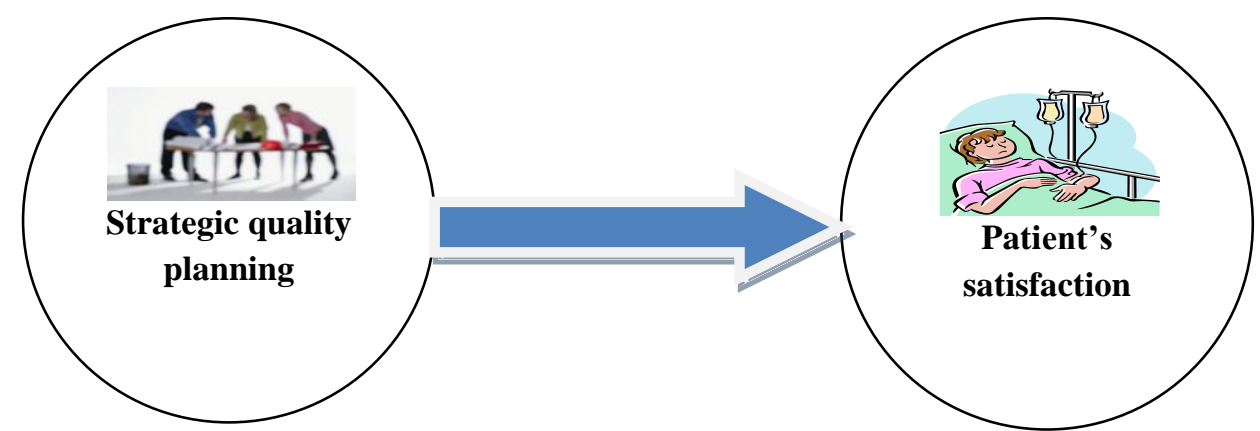

Fig 1.Strategic quality planning and patient's satisfaction: A conceptual model.

\section{Theoretical Framework And Hypothesis Generation}

The theoretical framework which has been developed for the generation of hypothesis is as follows (figure 1) 
From the above theoretical frame work the research hypothesis which was generated for the present study is as follows:

"Higher level of strategic quality planning leads to higher level of patient's satisfaction".

During the empirical testing following null hypothesis will be used:

"There is no relationship between the two variables".

\section{Methodology}

The methodology for the present research paper consisted of various leading private health care sectors which are located in twin cities of Pakistan (Rawalpindi \& Islamabad).

\section{Sampling Procedure}

A convenient type o sampling was used. A sample of 200 respondents(100 patients and 100 medical officers) was drown from the various private health care institutions located in the twin cities of Pakistan as per the following details in the below table.1

Table 1.Sampling Details.

\begin{tabular}{|lcc|}
\hline Private hospitals & Medical officers & Patients \\
\hline Rawalpindi & 50 & 50 \\
Islamabad & 50 & 50 \\
Total & 100 & 100 \\
Grand total & & 200 \\
\hline
\end{tabular}

\section{Tools For Data Collection}

For the measurement of strategic quality planning nine-item tool was being adopted from the detailed questionnaire which was developed by Ngware, M.W. et al. (2006) about quality management. The five item scale of Taylor, S.A., Baker, T.L. (1994) was used to examine the patients satisfaction level and for the investigation purpose a five point linkert scale was used.

\section{Reliability Of The Instruments}

The version 16.0 of SPSS was used for the analysis of data and the alpha reliability for both the instruments during the pre-testing ranged from 0.827-0.869 which indicates the strong internal consistency of the tools which was being used.

\section{Presentation And Analysis Of Data}

Demographic characteristics: medical officers and patients of private healthcare institutions of twin cities of Pakistan (Rawalpindi and Islamabad).

\section{Medical Officer's Survey}

The majority of medical officers in Rawalpindi city were less than 36 years and average ages of medical officers were 36.40 years whereas the majority of medical officers in Islamabad city were also less than 36 years and the average ages were 36.30 years.

In Rawalpindi it was found that there was almost equal proportion of both sexes: 58 male and 42 females. The situation was entirely different in case of Islamabad city a dominant majority (62\%) medical officers were female and $(38 \%)$ of the medical officers were male.

All the medical officers in both the cities were qualified and were brilliant in their field work.

\section{Patients Survey}

The patients of Rawalpindi city were equally distributed in all age groups (20 to $70+$ ) whereas the average ages of the patients were 46.74 years.

The education level of literate patients was $(54 \%)$ and the rest of $(46 \%)$ were illiterate.

The majority of patients there were male; $(58 \%)$ and(42\%) were female. On the other hand patients of Islamabad were also equally distributed in all age groups and the average ages of all patients were 45.12 years. The education level in Islamabad city was seen higher than Rawalpindi city (66\%) was literate whereas (34\%) wereilliterate. Islamabad city was found to have almost equal proportion of both sexes; $52 \%$ male and $48 \%$ female. 


\section{Hypothesis Testing}

The testing of hypothesis in this case was carried out with the application of regression coefficient. The following hypothesis were formulated for testing:

Research hypothesis: Higher the level of SQP (strategic quality planning) leads to higher level of patient's satisfaction.

Null Hypothesis:There is no relationship between the two variables.

According to the above data analysis a positive but weak relationship was found between the two variables resulting into the accepting the research hypothesis and rejecting the null hypothesis. The proposed hypothesized relationship was proved to be significant. The following could be the possible reason for the weak relationship between the two variables:

1. Patient's satisfaction may depend on other factors e.g. service quality offered by doctors concerns, nursing staff and other support administration staff in the hospital setting.

Table 2.Strategic Quality Planning and Patients Satisfaction

\begin{tabular}{|ccccc|}
\hline $\mathbf{R}$ & $\mathbf{r}^{2}$ & Ad. $^{2}$ & F Stat. & P value \\
\hline 0.230 & 0.053 & 0.043 & 5.479 & 0.021 \\
\hline
\end{tabular}

2. although strategic quality planning is being in practice in Pakistani private health care organizations, but Pakistan being a part of the third world, there could be some other sort of obstacles like poor salary structures as well as various other de-motivators which would cancel out the benefit of strategic quality planning and hence breaking the link between strategic quality planning and patients satisfaction.

\section{Conclusion}

Following are the conclusions which have been drawn from the above findings:

i. Strategic quality planning was being implemented but not up to the mark in the private health care institutions.

ii. Patients of Islamabad were highly satisfied as compared to Rawalpindi.

iii. A positive but weak relationship was found between strategic quality planning and patients satisfaction.

\section{Recommendations}

After concluding the above study, it is recommended that to examine the strategic quality planning implementation process the investigations may be designed, so that the future studies may be designed keeping into account the existing processes.

\section{Limitations}

This study was conducted with the twin cities of Pakistan more cities may be included for more generalization.

The data could have been analyzed on latest analysis tools like LISERAL etc.

\section{Websites:}

\section{References}

[1]. http://totalqualitymanagement.wordpress.com/2008/10/04/strategic-quality-planning/

[2]. http://en.wikipedia.org/wiki/Strategic_planning

[3]. http://aiqmindia.blogspot.com/2011/01/strategic-quality-planning-and.html

[4]. http://www.aaos.org/news/aaosnow/jun13/advocacy5.asp

\section{Journal Papers:}

[1] Employee empowerment and customer satisfaction: Empirical evidence from the banking sector of Pakistan by Hummayoun

Books: Naeem* and Muhammad Iqbal Saif.

[1] Strategic Quality Management: A Strategic Systems Approach to Continuous Improvement Loose Leaf by Mildred Golden Pryor J. Christopher White, Leslie A. Toombs. 